\title{
Assessment Of Schoolchildren's Temporomandibular Joint Sounds Associated With Bruxism
}

\author{
Ahmed Fathy Arafa ${ }^{1}$, Nawras Maher Mostafa ${ }^{2}$ and Shady Ahmed Moussa ${ }^{3^{*}}$ \\ ${ }^{1} B D S, M S c, D D S$, Oral \& Maxillofacial Department, Zagazig University, Egypt \\ ${ }^{2} B D S$, MSc, Restorative \& Advanced Aesthetic Dentistry, Iraq \\ ${ }^{3} B D S, M S c, D D S, M R A C D S(D P H)$, Pediatric Dentistry \& Oral Health Department, Zagazig University, Egypt
}

Received: December 13, 2018; Accepted: January 08, 2019; Published: January 11, 2019

*Corresponding author: Dr Shady Ahmed Moussa, Pediatric Dentistry \& Oral Health department, Zagazig University, Egypt. Email : shashyshaty@ yahoo.com

\begin{abstract}
Many studies have explained temporomandibular joint (TMJ) sounds in children are frequent with TMJ disorder. In addition to multiple divergent findings are designed to evaluate the relationship between bruxism and TMJ disorder in children.

Aim: study was designed and conducted to assess the possible relationship between bruxism and joint sounds in schoolchildren.

Subjects and Methods: The sample comprised 60 schoolchildren participants between 6 to 10 years of age, of whom 30 children with bruxism as study group G1 and another 30 without bruxism as a control group G2 who were scheduled and randomly selected for treatment at (Outpatient Dental Clinics, Zagazig University Hospital). Examiner performed assessment who was blinded allocation of the groups. Assessment involved of (manual palpation, lateral and dorsal extra-auricular auscultation of TMJ by stethoscope for detecting of joint sounds, differentiating between joint sounds as a click/pop or crepitation) Three readings were performed on each participant Collected data were checked, entered and statistically analyzed to test different variables by chi-square test with the level of significance $(\mathrm{p}<$ 0.05).
\end{abstract}

Results: There were statistically significant association between joint sounds with regarding to bruxism and age, which showed the higher prevalence rates of joint sounds were found in children aged eight to ten years in comparison to those aged sex and seven years. However, there were statistically insignificant association between joints sounds and type in relation to gender.

Conclusion: The bruxism in children may be associated with the symptoms of joint sounds with significant association regarding to age.

Keywords: Bruxism; Temporomandibular Joint; Child; bruxism; TMJ sound.

\section{Introduction}

The prevalence of TMJ disorder is not well known, with a frequency ranging from 16.3 to $68 \%$ [1-3]. There are variations regarding the TMJ disorder prevalence from center to center and from country to another depending on evaluation and diagnosis methods of TMJ disorder that is beside the contributory variations such as sample size, sample selection, the age group heterogeneity and difference in method of examination used in each study $[1,4,5]$. The relationship between primary and mixed dentition and TMJ disorders in children aged 4 were evaluated by (Muhtarodullary $M$, et al. [6]) who found that the signs and symptoms such as headache, joint sound, pain in TMJ area, restricted mouth opening, deviation-deflection, palpatory tenderness in TMJ, masticatory muscle tenderness were increased from the primary to the mixed dentition group. Unfortunately, the differences not significant between the two groups except joint sounds, which was more significant in mixed dentition group. (Chauhan D, et al. [7]) reported that the TMJ disorder prevalence increased by increasing the age was evident but without statistically significant results $(\mathrm{P}<0.12)$, it was $1.6 \%$ for the 9 years age group and $3.5 \%$ in 12 years age group. Females were affected eight times more than the males; $4.8 \%$ to $6 \%$. Children belonging to urban background were affected more, $3.2 \%$ as compared with $2 \%$ of rural children $(\mathrm{P}<0.21)$. However, it is statically not significant. The prevalence of TMJ disorder in southern Portuguese children and adolescents aged 5-19 years and its association with emotional stress was studied by (Minghelli B, et al.[8]) their results were showed high prevalence of TMJ disorder (25.2\%). Regarding to the emotional stress those who considered tense or nervous had higher probability to develop TMJ disorder. Moreover, the girls significantly prevalence of developing TMJ disorder than boys $(p<0.001)$, also found the older aged group had higher probability of developing the disorder $(\mathrm{p}<0.001)$ [9]. In Brazilian adolescents who had TMJ disorder symptoms showing the girls had a significantly higher prevalence of symptoms than boys. The girls also had a significantly higher prevalence of myofascial pain and disc displacement with reduction. The myofunctional pain appear the more prevalent symptom (10.3\%), followed by disc displacement with reduction (8.0\%) arthralgia (3.5\%), and myofascial pain with opening limitations $(0.2 \%)$. Tense or nervous considered the most common symptom[10]. Bruxism is a very common condition in $85 \%-90 \%$ of the population 
[11] and the term is defined as a repetitive jaw muscle activity characterized by clenching or grinding of the teeth and/or by bracing or thrusting of the mandible[12]. To date, three definitions of sleep bruxism have been provided by the American Academy of Sleep Medicine (AASM). In 1990, the International Classification of Sleep Disorders (ICSD) defined sleep bruxism within the category of parasomnias (or disorders that intrude on sleep, but are not associated with complaints of insomnia or sleepiness) as a stereotyped movement disorder characterized by grinding or clenching of the teeth during sleep [13]. In the second edition of the ICSD in 2005, sleep bruxism was categorized as a sleep-related movement disorder and defined as an oral parafunctional activity characterized by tooth grinding or jaw clenching during sleep, usually associated with sleep arousals 14 . Recently, an updated definition of general bruxism was adopted for the third edition of the ICSD: a repetitive jaw-muscle activity characterized by clenching or grinding of the teeth and/or by bracing or thrusting of the mandible15. Bruxism para functional activity has harmful effects on the teeth, periodontium, masticatory muscles and temporomandibular joint TMJ which is often found in children and adolescents which also have psychological effects [16-18]. The bruxism consequences has direct relation to the changes that occur in the masticatory muscles which often associated with discomfort and pain in joint are the main complaints, along with difficulty chewing, joint luxation, uncoordinated jaw movements, degenerative alteraᄀtions in the joint, restricted/deviated mandibular movements and joint sounds 19,20. Bruxism is a rhythmic or sustained contraction of the jaw closing muscles produces tooth movement without awareness of patient which has two types of with different etiopathogenesis: asleep and awake bruxism $[11,21,22]$. A repetitive sleep movement disorder primarily characterized by rhythmic masticatory muscle activity and by occasional tooth grinding and is associated with brief cardiac and brain reactivation23. Instead, awake bruxism is characterized by only clenching type activity and is associated with psychosocial factors [24]. Classification of joint sounds are proposed which takes into account the nature of the sounds as a single, explosive noise (click or pop) or a continuous grating noise (crepitus), their quality (hard or soft), their positions in relation to mandibular movement (near, middle or wide) and whether the sounds occur on opening or closing of the jaws. There is consensus of clicks are generally as the result of the impact between the condyle of mandible and the temporal component of the TMJ after its rapid passage through the posterior band of the joint disc 25. Crepitus is found in more advanced stages of TMJ disorder and is associated with a degenerative condition 25. However, many studies have explained sounds in the TMJ are frequent in children with TMJ disorder [26-29]. Moreover, divergent findings are reported to demonstrate the relationship between bruxism and TMJ disorder in children [29]. Considering the consequences of these aspects to the TMJ, the present study was conducted to investigate the possible relationship between bruxism and joint sounds in schoolchildren.

\section{Subjects and Methods}

According to World Medical Association, declaration of Helsinki [30], study population and ethical local institutional approval for study sample comprised 60 participants aged from six to ten years, scheduled for treatment at (Outpatient Dental Clinics, Zagazig University Hospital, Egypt). Patients with debilitating diseases or neurological disorder, with any type of maloc $\neg$ clusion, undergoing orthodontic treatment orofacial asymmetry or who examined for possible ear infections were excluded from the study. All participants have the first permanent molars in the Angle Class I occlusal relationship as inclusion criteria. First group (G1) was composed of 30 children with some sign of bruxism based on the criteria of AASM [15] parental report of clenching and/or grinding of the teeth and incisal and/or occlusal tooth wear. Another group (G2) consisted of 30 randomly selected children with no signs or symptoms of bruxism. All parents or legal guardians received adequate information and written consent to participate in the study. The same examiner performed the clinical evaluation undergone a training exercise and allocated participants in both groups blindly.

\section{Joint sounds analysis}

1-Unfortunately, joint sounds were analyzed by occurrence of a click/pop and crepitus through lateral and dorsal extra-auricular exam. Digital palpation of both TMJs was performed along with auscultation by stethoscope with diaphragm-endpiece. Digital palpation is valuable in detection of irregular TMJ movements due for instance to displacement of the disc [31,32] and it is a valuable complement to auscultation but is not recording the same variable. 2- The participants were asked to open and close their mouth several times to detect the presence or absence of joints sounds and classify their type. Each child performed the different movements at least three times. 3- When one or more signs were detected by auscultation, the child was classified as positive for joint sounds.

\section{Result}

Checked data were collected, tabulated, entered and analyzed by using SPSS (version 22) and presented as a quantitative variable. Chi-Square test used for detecting distribution that is expected between different variable (bruxism, age and sex) to presence and type of TMJ sounds. $(\mathrm{P}<0.05)$ was considered statistically significant.

(Table 1,2): Shows a total 60 participant aged six to ten years were examined 26 participants were males (43.33\%) and 34 participants were females (56.67\%). There was no statically significant association was found between joints sounds and sex $(\mathrm{P}>0.05)$. However, a significant association was found regarding to age as a greater percentage of children at eight to ten years of age had joint sounds and a lesser percentage at six to seven years of age $(\mathrm{P}<0.05)$. 


\begin{tabular}{|c|c|c|c|c|c|c|}
\hline & & & $\begin{array}{c}\text { Present } \\
\text { Joint } \\
\text { sounds }\end{array}$ & $\begin{array}{c}\text { Absent } \\
\text { Joint } \\
\text { sounds }\end{array}$ & Total & p-value \\
\hline \multirow{2}{*}{ Sex } & Male & $\begin{array}{l}\mathrm{n} \\
\%\end{array}$ & $\begin{array}{c}9 \\
34.62 \%\end{array}$ & $\begin{array}{c}17 \\
65.38 \%\end{array}$ & $\begin{array}{c}26 \\
43.33 \%\end{array}$ & \multirow{3}{*}{0.3326} \\
\hline & Female & $\begin{array}{l}\mathrm{n} \\
\%\end{array}$ & $\begin{array}{c}16 \\
47.06 \%\end{array}$ & $\begin{array}{c}18 \\
52.94 \%\end{array}$ & $\begin{array}{c}34 \\
56.67 \%\end{array}$ & \\
\hline Total & & $\begin{array}{l}\mathrm{n} \\
\%\end{array}$ & $\begin{array}{c}25 \\
41.67 \%\end{array}$ & $\begin{array}{c}35 \\
58.33 \%\end{array}$ & $\begin{array}{c}60 \\
100 \%\end{array}$ & \\
\hline \multicolumn{7}{|c|}{$\mathrm{X}^{2^{\mathrm{x}}}$ test $=0.9386$} \\
\hline \multicolumn{7}{|c|}{ Statistically insignificant $(p>0.05)$} \\
\hline
\end{tabular}

\begin{tabular}{|c|c|c|c|c|c|c|}
\hline & & & $\begin{array}{l}\text { Present } \\
\text { of Joint } \\
\text { sounds }\end{array}$ & $\begin{array}{l}\text { Absent } \\
\text { of Joint } \\
\text { sounds }\end{array}$ & Total & p-value \\
\hline \multirow{10}{*}{ Age } & \multirow[t]{2}{*}{6 years } & $\mathrm{n}$ & 4 & 18 & 22 & \multirow{12}{*}{$0.007015^{*}$} \\
\hline & & $\%$ & $18.18 \%$ & $81.82 \%$ & $36.66 \%$ & \\
\hline & \multirow[t]{2}{*}{7 years } & $\mathrm{n}$ & 1 & 6 & 7 & \\
\hline & & $\%$ & $14.29 \%$ & $85.71 \%$ & $11.67 \%$ & \\
\hline & \multirow[t]{2}{*}{8 years } & $\mathrm{n}$ & 7 & 4 & 11 & \\
\hline & & $\%$ & $63.64 \%$ & $36.36 \%$ & $18.33 \%$ & \\
\hline & \multirow[t]{2}{*}{9 years } & $\mathrm{n}$ & 9 & 4 & 13 & \\
\hline & & $\%$ & $69.23 \%$ & $30.77 \%$ & $21.67 \%$ & \\
\hline & \multirow{2}{*}{$\begin{array}{c}10 \\
\text { years }\end{array}$} & $\mathrm{n}$ & 4 & 3 & 7 & \\
\hline & & $\%$ & $57.14 \%$ & $42.86 \%$ & $11.67 \%$ & \\
\hline \multirow{2}{*}{\multicolumn{2}{|c|}{ Total }} & $\mathrm{n}$ & 25 & 35 & 60 & \\
\hline & & $\%$ & $41.67 \%$ & $58.33 \%$ & $100 \%$ & \\
\hline
\end{tabular}

\section{$\mathrm{X}^{2^{\mathrm{x}}}$ test $=14.0893$}

*statistically significant $(\mathrm{p}<0.05)$

(Table 3,4): shows that $45 \%(n=25)$ had joint sounds and $55 \%(n=35)$ exhibited no sounds during any of the auscultations and examination. There was statically significant association between joint sounds and bruxism $(\mathrm{P}<0.05)$, as $56.67 \%(\mathrm{n}=17)$ of the participants with joint sounds and had bruxism at the same time. Among those with joint sounds $88 \%(n=22)$ exhibited a click/pop and $12 \%(n=3)$ exhibited crepitus which has statically insignificant relation with gender $(\mathrm{P}>0.05)$.

\begin{tabular}{|c|c|c|c|c|c|}
\hline \multirow[b]{2}{*}{ Bruxism } & \multicolumn{3}{|c|}{ Joint sounds } & \multirow[b]{2}{*}{ Total } & \multirow[b]{2}{*}{ p-value } \\
\hline & \multicolumn{2}{|c|}{$\begin{array}{l}\text { Present of Joint } \\
\quad \text { sounds }\end{array}$} & \multirow{2}{*}{$\begin{array}{c}\begin{array}{c}\text { Absent of Joint } \\
\text { sounds }\end{array} \\
13\end{array}$} & & \\
\hline & $\mathrm{n}$ & 17 & & 30 & \multirow{6}{*}{$0.0184^{*}$} \\
\hline $\begin{array}{l}\text { (G1) with } \\
\text { Bruxism }\end{array}$ & $\%$ & $56.67 \%$ & $43.33 \%$ & $50 \%$ & \\
\hline \multirow[b]{2}{*}{$\begin{array}{c}\text { (G2) } \\
\text { without } \\
\text { Bruxism }\end{array}$} & $\mathrm{n}$ & 8 & 22 & 30 & \\
\hline & $\%$ & $26.67 \%$ & $73.33 \%$ & $50 \%$ & \\
\hline \multirow[b]{2}{*}{ Total } & $\mathrm{n}$ & 25 & 35 & 60 & \\
\hline & $\%$ & $41.67 \%$ & $58.33 \%$ & $100 \%$ & \\
\hline
\end{tabular}

$\mathrm{X}^{\mathrm{X}^{\mathrm{x}}}$ test $=5.5543$

*statistically significant $(\mathrm{p}<0.05)$

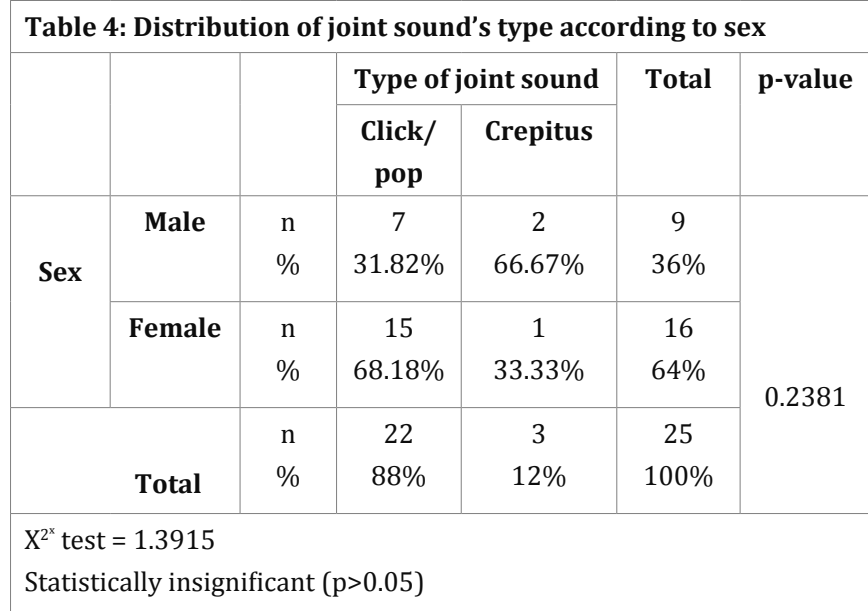

\section{Discussion}

Although, the lack of relation between TMJ dysfunction and clicking does not mean that variable is not important, the main methods used in recording TMJ sound are palpation and auscultation with or without stethoscope [33.34]. During palpation, the low frequency vibrations of high amplitude may be possibly felt and heard. However, the human ear is most sensitive for vibrations in the range $1000-3000 \mathrm{~Hz}$ that most probably cannot be felt by palpation. TMJ sounds frequencies involved in that range and higher $[35,36]$ and without auscultation they pass unnoticed at palpation. Therefore, palpation cannot replace auscultation in recording of TMJ sound. TMJ sounds can sometimes be heard with the naked ear. In the present study, it could not be heard without the help of a stethoscope. The stethoscope does not amplify the sound but pass it to be possible for the examiner to hear the sound about as well as if he listens with the naked ear touching the skin over the TMJ area. Avoiding to touch the patient was actually the original rationale for using a stethoscope. 
of shear stresses is similar to that of the principal stresses, being higher in the anterior and intermediate zones, mainly due to the high compressive stresses observed in those zones. Additionally, the inferior surface suffers the highest shear stresses because the tensile and compressive stresses are higher in that surface. After 5 min of sustained clenching, the tensile, compressive and shear stresses in the TMJ disc are higher than those at the beginning. This result is in accordance with the measurements made by (Kuboki, et al. [44]) where clenching induced a significant reduction of the joint space and the sustained condition remarkably increased that change. Joint pain, occasional headaches and sound produced by bruxism that explained by overloading the temporomandibular joint45, and more precisely by shear stresses in the articular disc, which constitute the source of the damage induced to chondrocytes46. Joint sounds are related to structural and/or functional changes in the biomechanics of the TMJ and can even be indicative of degeneration of the joint $[25,29,47]$. Epidemiological studies involving a convenience sample suggest a strong relationship between bruxism and TMJ disorder [48]. According to (Morrow, et al. [49]), TMD often results in pain, joint sounds and limited condyle movements when opening and closing the mouth. A sound in the TMJ is a frequently reported symptom and a clinically proven sign in epidemiological investigations [3]. However, divergent findings are reported regarding to joint sounds in individuals with bruxism. In the present study, a significant was found between both conditions that can be explained by parafunctional activity, which is common in children and alters the movements of the jaw and its functions that completely agreed with (Motta LJ, et al. [50]) Multiple clinical exams confirmed that many children were aware of sounds in the TMJ 43. In other studies, the authors reported that the greater severity degree of bruxism the more increase in the frequency of joint sounds 47 and that joint sounds are a significant predictor of TMJ disorder[51]. The sleep bruxism may be one of the factors of TMJ disorder [52]. (Molina, et al. [53]) found an correlation between sounds in the TMJ and self-reported bruxism. In the present study, joint sounds were associated with increase in age especially over eight years. These sounds stem from changes in the shape of the TMJ that begin to occur at approximately six years of age [29]. Moreover, these sounds often occur in children with no other signs or symptoms of TMJ disorder. The clicking sound occurs due to changes in the location of the joint disc in the fossa of the temporal bone, indicating that the disc was in a forward position and returned to its correct position during the vertical movement of the jaw [25]. However, it is unknown whether joint sounds subsequently develop as pathological symptoms29. The prevalence of bruxism increases significantly with age [54] while the results of the present study confirm that TMJ sounds prevalence increases with age which occur with high prevalence after six year but, in other opinion, suggested that TMJ sounds occur with high prevalence already in four to six year old children $[55,56]$ and that are significantly associated with a high number of other signs of TMJ dysfunction and related pain. This may seem contrary to (Kirveskari, et al. [57]) who reported very few children with five year olds have joint sounds without palpation tenderness. The crepitus sounds with low prevalence of this joint noise in children explained by it often occurs in cases of osteoarthrosis of the TMJ that is very rare in children $[25,50]$. It is difficult to make accurate comparisons due to variations between studies in recording methods, demographic characteristics and definition of variables and that they are significantly associated with a high number of other signs of TMJ dysfunction and related pain.

\section{Conclusion}

Results demonstrate higher prevalence rates of joint sounds were found in children aged of eight to ten in comparison to those aged of six and seven. The main value of present study is that demonstrates a possible association between bruxism and joint sounds in schoolchildren which our clinical relevance finding suggests this direct relation between bruxism in children and the severity and progression of joint sounds' symptoms.

\section{References}

1. Sena MF, Mesquita KS, Santos FR. Prevalence of temporomandibular dysfunction in children and adolescents. Rev Paul Pediatr 2013;31(4):538-545. doi: 10.1590/S0103-05822013000400018

2. Sönmez H, Sari S, Oksak Oray G, Camdeviren H. Prevalence of temporomandibular dysfunction in Turkish children with mixed and permanent dentition. J Oral Rehabil. 2001;28(3):280-5.

3. Emodi-Perlman A, Eli I, Friedman-Rubin P, Goldsmith C, Reiter S, Winocur E. Bruxism, oral parafunctions, anamnestic and clinical findings of temporomandibular disorders in children. J Oral Rehabil. 2012;39(2):126-135. doi: 10.1111/j.1365-2842.2011.02254.x

4. Ross DM, Ross SA. The importance of type of question, psychological climate and subject set in interviewing children about pain. Pain. 1984;19(1):71-79.

5. Tecco S, Crincoli V, Di Bisceglie B, Saccucci M, Macrí M, Polimeni A, et al. Signs and symptoms of temporomandibular joint disorders in Caucasian children and adolescents. Cranio. 2011;29(1):71-79. doi: 10.1179/crn.2011.010

6. Muhtarodullary M, Demirel F, Saygili G. Temporomandibular disorders in Turkish children with mixed and primary dentition: prevalence of signs and symptoms. The Turkish Journal of Pediatrics. 2004;46(2):159-163.

7. Deepak Chauhan, Jairam Kaundal, Suneet Karol, Tripti Chauhan. Prevalence of signs and symptoms of temporomandibular disorders in urban and rural children of northern hilly state, Himachal Pradesh, India: A cross sectional survey. 2013;4(1):21-25.

8. Beatriz Minghelli, Iara Cardoso, Melani Porfírio, Roberta Gonçalves, Sabina Cascalheiro, Vera Barreto, et al. Prevalence of Temporomandibular Disorder in Children and Adolescents from Public Schools in Southern Portugal. North Am J Med Sci. 2014;6(3):126-132. doi: 10.4103/1947-2714.128474

9. Vegard Ostensjo, Ketil Moen, Trond Storesund, and Annika Rosen. Prevalence of Painful Temporomandibular Disorders and Correlation to Lifestyle Factors among Adolescents in Norway. Hindawi Pain Research and ManagementVolume 2017. doi: 10.1155/2017/2164825 
10. Bertoli FMP, Bruzamolin CD, Pizzatto E, Losso EM, Brancher JA, de Souza JF. Prevalence of diagnosed temporomandibular disorders: A cross-sectional study in Brazilian adolescents. PLoS ONE. 2018;13(2). doi: 10.1371/journal.pone.0192254

11. Bader G, Lavigne G. Sleep bruxism: an overview of an oromandibular sleep movement disorder. Sleep Med Rev. 2000;4(1):27-43.

12. Lobbezoo F, Ahlberg J, Glaros AG, et al. Bruxism defined and graded: an international consensus. J Oral Rehabil. 2013;40(1):2-4. doi: 10.1111/ joor.12011

13. Diagnostic Classification Steering Committee. The international classification of sleep disorders: diagnostic and coding manual. Westchester, IL.: American Academy of Sleep Medicine; 1990.

14. Sleep related bruxism. In: International classification of sleep disorders: diagnosis and coding manual. 2nd edition. Westchester, IL.: American Academy of Sleep Medicine; 2005:189-92.

15. Sleep related bruxism. In: International classification of sleep disorders. 3rd edition. Darien, IL.: American Academy of Sleep Medicine; 2014.

16. Serra-Negra JM, Paiva SM, Seabra AP, Dorella C, Lemos BF, Pordeus IA. Eur Arch Paediatric Dent. 2010;11(4):192-195.

17. Insana SP, Gozal D, McNeil DW, Montgomery-Downs HE. Community based study of sleep bruxism during early childhood. Sleep Med. 2013;14(2):183-188.

18. Ferreira-Bacci Ado V, Cardoso CL, Díaz-Serrano KV. Behavioral problems and emotional stress in children with bruxism. Braz Dent J. 2012;23(3):246-251.

19. Fernandes G, Franco AL, Siqueira JT, Gonçalves DA, Camparis CM. Sleep bruxism increases the risk for painful temporomandibular disorder, depression and non-specific physical symptoms. J Oral Rehabil. 2012;39(7):538-544.

20. Thilander B, Rubio G, Pena L, de Mayorga C. Prevalence of temporomandibular dysfunction and its association with maloccusion in children and adolescents: an epidemiologic study related to specified stages of dental development. Angle Orthod. 2002;72(2):146-154.

21. Manfredini D, Lobbezoo F. Role of psychosocial factors in the etiology of bruxism. J Orofac Pain. 2009;23(2):153-166.

22. Lavigne GJ, Kato T, Kolta A, Sessle BJ. Neurobiological mechanisms involved in sleep bruxism. Crit Rev Oral Biol Med. 2003;14(1):30-46.

23. Lavigne GJ, Huynh N, Kato T, Okura K, Adachi K, Yao D et al. Genesis of sleep bruxism: motor and autonomic cardiac interactions. Arch Oral Biol. 2007;52(4):381-384.

24. Manfredini D, Lobbezoo F. Relationship between bruxism and temporomandibular disorders: a systematic review of literature from 1998 to 2008. Oral Surg Oral Med Oral Pathol Oral Radiol Endod. 2010;109(6):26-50. doi: 10.1016/j.tripleo.2010.02.013

25. Farsi NM. Symptoms and signs of temporomandibular disorders and oral parafunctions among Saudi children. J Oral Rehabil 2003;30(12):1200-1208.

26. Vanderas AP, Papagiannoulis L. Multifactorial analysis of the aetiology of craniomandibular dysfunction in children. Int J Paediatr Dent. 2002;12(5):336-346
27. Sari S, Sonmez H. Investigation of the relationship between oral parafunctions and temporomandibular joint dysfunction in Turkish children with mixed and permanent dentition. J Oral Rehabil. 2002;29(1):108-112.

28. Castelo PM, Gaviao MB, Pereira LJ, Bonjardim LR. Relationship between oral parafunctional/nutritive sucking habits and temporomandibular joint dysfunction in primary dentition. Int $\mathrm{J}$ Paediatr Dent. 2005;15(1):29-36.

29. Barbosa Tde S, Miyakoda LS, Pocztaruk Rde L, Rocha CP, Gaviao MB. Temporomandibular disorders and bruxism in childhood and adolescence: review of the literature. Int J Pediatr Otorhinolaryngol. 2008;72(3):299-314. doi: 0.1016/j.ijporl.2007.11.006

30. World Medical Association Declaration of Helsinki, Ethical Principles for Medical Research, Involving Human Subjects. J Amer Medi Asso. 2013

31. Eriksson L, Westesson PL, Sjöberg H. Observer performence in describing temporomandibular joint sounds. J Craniomandib Pract. 1987;5(1):32-35.

32. Dworkin SF, Huggins KH, LeResche L, Von Korff M, Howard J, True-love E, et al. Epidemiology of signs and symptoms in temporomandibular disorders: clinical signs in cases and controls. J Am Dent Assoc. 1990;120(3):273-281.

33. Ishigaki S, Bessette RW, Maruyama T. A clinical study of temporomandibular joint TMJ vibrations in TMJ dysfunction patients. J Craniomandib Pract. 1993;11:7-13.

34. Mohl ND, Lund JP, Widmer CG, McCall WD Jr. Devices for the diagnosis and treatment of temporomandibular disorders. Part II: Electromyography and sonography. J Prost Dent. 1990;63(3):332-336.

35. Brown ML, Williams WJ, Widmalm SE. Automatic classification of temporomandibular joint sounds. In Intelligent Engineering Systems Through Artificial Neural Networks. 1994;4:725-730. Eds. C. H. Dagli, B. R. Férnandez, J. Ghosh \& R. T. S. Kumara. Asme Press, New York.

36. Widmalm SE, Williams WJ, Christiansen RL, Gunn SM, Park DK. Classification of temporomandibular joint sounds based upon their reduced interference distribution RID. J Oral Rehab 1996;23(1):35-43.

37. Jarvis C. Physical Examination and Health Assessment. W. B. Saunders Company, Philadelphia. 1992;168-170.

38. Ertel PY, Lawrence M, Brown RK, Stern AM. Stethoscopic acoustics. II. Transmission and filtration patterns. Circulation. 1966;34:899-909.

39. Egermark-Eriksson I, Carlsson GE, Ingervall B. Prevalence of mandibular dysfunction and orofacial parafunction in 7-, 11- and 15-year-old Swedish children. Europ J Orthod. 1981;3(3):163-172

40. Eriksson L, Westesson PL, Sjöberg H. Observer performence in describing temporomandibular joint sounds. J Craniomandib Pract 1987;5(1):32 -35

41. Nagamatsu-Sakaguchi C, MInakuchi H, Clark GT. Relationship between the Frequency of Sleep Bruxism and the Prevalence of Signs and Symptoms of TMD. J Int Prost. 2008;21(4):292-298.

42. Manfredini D, Restrepo C, Diaz-Serrano K, Winocur E, Lobbezzo F. Prevalence of sleep bruxism in children:a systematic review of the literature. J Oral Rehabil. 2013;40(8):631-642. 
43. Okeson JP. Mechanics of Mandibular Movement. In, Dolan J, Pendill J, editors. Management of TMD and occlusion. 6th edition St Louis (M0):Mosby. 2008;151-9.

44. Kuboki T, Azuma Y, Orsini MG, Takenami Y, Yamashita A. Effect of sustained unilateral clenching on the temporomandibular joint space. Oral Surg Oral Med Oral Pathol Oral Radiol Endod. 1996;82(6):616624.

45. Lavigne GJ, Huynh N, Kato T, Okura K, Adachi K, Yao D, et al. Genesis of sleep bruxism: motor and autonomiccardiac interactions. Arch Oral Biol. 2007;52(4):381-384.

46. Smith RL, Carter DR, Schurman DJ. Pressure and shear differentially alter human articular chondrocyte metabolism: a review. Clin Orthop Relat Res. 2004;427(Suppl):S89-S95.

47. Baba K, Haketa T, Sasaki Y, Ohyama T, Clark GT. Association between masseter muscle activity levels recorded during sleep and signs and symptoms of temporomandibular disorders in healthy young adults. Journal of Orofacial Pain. 2005;19(3):226-231.

48. Schiffman EL, Fricton JR, Haley D. The relationship of occlusion, parafunctional habits and recent life events to mandibular dysfunction in a non-patient population. J Oral Rehabil. 1992;19(3):201-223.

49. Morrow D, Tallents RH, Katzberg RW, Murphy WC, Hart TC. Relationship of other joint problems and anterior disc position in symptomatic TMD patients and in asymptomatic volunteers. J Orofac Pain. 1996;10(1):15-20.
50. Motta LJ, Silva PFC, Godoy CHL, Bortoletto CC, Garcia PRÁ, Silva FC, et al. Assessment of temporomandibular joint sounds in children with bruxism. Rev. CEFAC. 2015;17(1):111-115.

51. Egermark I, Carlsson GE, Magnusson T. A 20-year longitudinal study of subjective symptoms of temporomandibular disorders from childhood to adulthood. Acta Odontol Scand. 2001;59(1):40-48.

52. Huang GJ, LeResche L, Critchlow CW, Martin MD, Drangsholt MT Risk factors for diagnostic subgroups of painful temporomandibular disorders (TMD). J Dent Res. 2002;81(4):284-288.

53. Molina OF, dos Santos Jr, Nelson SJ, Nowlin T. A clinical study of specific signs and symptoms of CMD in bruxers classified by the degree of severity. Cranio. 1999;17(4):268-279.

54. Petit D, Touchette E, Tremblay RE, Boivin M, Montplaisir J. Dyssomnias and parasomnias in early childhood. Pediatrics. 2007;119(5):10161025

55. Widmalm SE, Christiansen RL, Gunn SM, Hawley LM. Prevalence of signs and symptoms of cranio mandibular disorders and of orofacial parafunction in 4-6 year old African-American and Caucasian children. J Oral Rehab. 1995;22(2):87-93.

56. Widmalm SE, Gunn SM, Christiansen RL, Hawley LM. Association between CMD signs and symptoms, oral parafunctions, race and sex, in 4-6 year old African-American and Caucasian children. J Oral Rehab. 1995;22(2):95-100.

57. Kirveskari P, Alanen P, Jämsä T. Functional state of the stomatognathic system in 5, 10 and 15 year old children in southwestern Finland. Proc Finn Dent Soc. 1986;82(1):3-8. 